\title{
The structure and optical properties of lead-free transparent KNLTN-La 0.01 ceramics prepared by conventional sintering technique
}

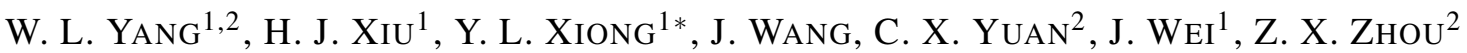 \\ ${ }^{1}$ Department of Applied Science, Harbin University of Science and Technology, Harbin 150080, PR China \\ ${ }^{2}$ Department of Physics, Harbin Institute of Technology, Harbin, 150001, PR China
}

\begin{abstract}
$\left(\mathrm{Na}_{0.52} \mathrm{~K}_{0.44} \mathrm{Li}_{0.04}\right)_{0.97} \mathrm{La}_{0.01} \mathrm{Ta}_{0.20} \mathrm{Nb}_{0.80} \mathrm{O}_{3}\left(\mathrm{KNLTN}-\mathrm{La}_{0.01}\right)$ lead-free subtransparent ceramics was prepared by a conventional sintering technique. The structure and the optical properties of the ceramics were investigated. The room temperature crystallographic indexing revealed the $\mathrm{ABO}_{3}$ perovskite type, tetragonal phase and $\mathrm{P} 4 \mathrm{~mm}$ point group in the ceramics. The surface and fractured surface SEM micrographs showed a dense microstructure with few micropores in KNLTN-La 0.01 ceramics, which was obviously better than for the pure KNLTN ceramics. The refractive indexes of the films were investigated by an ellipsometer and the results show that the KNLTN-La 0.01 subtransparent ceramics reveals significant wavelength dependent dispersion. The refractive index ranges from 2.14 to 2.06 with the wavelength increase from $380 \mathrm{~nm}$ to $900 \mathrm{~nm}$. The dispersive behavior was analyzed by three parameters of Cauchy dispersion model and the values of the parameters A, B and C are $2.0610 \pm 0.0005,0.0054 \pm 0.0003$ and $0.00069 \pm 0.00004$, respectively.
\end{abstract}

Keywords: lead-free ceramics; subtransparent ceramics; optical properties; refractive index dispersion; Cauchy model

(C) Wroclaw University of Technology.

\section{Introduction}

Highly integrated electro-optic devices have developed rapidly as a key technology of the future data communication systems [1-5]. Electro-optic crystals, films and transparent polycrystalline ceramics, with good optical transparency and strong electro-optic effects, have received a great deal of attention due to their wide range of applications to optical switches, modulators, optical filters and data processing devices [6-8]. Their crystallographic structure is of perovskite type with a formulation of $\mathrm{ABO}_{3}$ [2]. Typical examples of this family include $\mathrm{LiNbO}_{3}(\mathrm{LN}), \mathrm{Pb}_{1-x} \mathrm{La}_{x}$ $\left(\mathrm{Zr}_{y} \mathrm{Ti}_{1-y}\right)_{1-x / 4} \mathrm{O}_{3}(\mathrm{PLZT}), \quad \mathrm{Pb}\left(\mathrm{Mg}_{1 / 3} \mathrm{Nb}_{2 / 3}\right) \mathrm{O}_{3}-$ $\mathrm{PbTiO}_{3}$ (PMN-PT), $\mathrm{Pb}\left(\mathrm{Zn}_{1 / 3} \mathrm{Nb}_{2 / 3}\right) \mathrm{O}_{3}-\mathrm{PbTiO}_{3}$ (PZN-PT), and $\left(\mathrm{K}_{0.5} \mathrm{Na}_{0.5}\right)_{1-x} \mathrm{Li}_{x} \mathrm{Nb}_{1-x} \mathrm{Bi}_{x} \mathrm{O}_{3}$ (KNN-LB) lead-free crystals, films and optoceramics $[2,6,9,10]$. However, there are several drawbacks of those crystals and films, such as

*E-mail: xyling1964@163.com complex and expensive preparation, frangibility, low electro-optic effects, small available sizes and high temperature dependency, which make them difficult for widespread applications [6]. Opto-ceramics, a family of special transparent oxide materials, has many advantages, such as strong electro-optic response and reasonable size, which make them a good choice for the materials of the future electro-optic devices in digital communication systems [2-4, 6, 11, 12].

PLZT transparent ceramics is one of the few ceramics, which could be used in the actual optical applications at present. Although PLZT (i.e. $8 / 65 / 35$ and $9 / 65 / 35$ ) ceramics has much higher electro-optic coefficient than $\mathrm{LiNbO}_{3}$ single crystals, and higher transparency than other ferroelectric materials, the volatile element - lead - is toxic and harmful to human health [2, 13, 14]. Recently, KNN based lead-free transparent ceramic have successfully been prepared by K. W. Kwok using hotpress sintering $[6,9,10]$. In order to achieve higher transparency, $\mathrm{Li}, \mathrm{Ta}$ and $\mathrm{Bi}$ are usually introduced 
into A and/or B sites of the KNN solid solutions, respectively. However, high optically transparent ceramics should be of high purity and high density. To achieve high purity final products it is necessary to use high purity precursor powders, and to get high density various sintering technologies have been employed, such as high-pressure (HP) sintering, high isostatic pressure (HIP) sintering, vacuum sintering and spark plasma sintering (SPS). At the same time, various wet chemical synthesis routes have be used to produce precursor powders on submicron or even nanometer scales, with significantly improved sinterability [2]. However, optical ceramics prepared by conventional ceramics sintering technique and its refractive index dispersive behavior have rarely been studied and reported.

In this paper, the $\left(\mathrm{Na}_{0.52} \mathrm{~K}_{0.44} \mathrm{Li}_{0.04}\right)_{0.97}$ $\mathrm{La}_{0.01} \mathrm{Ta}_{0.20} \mathrm{Nb}_{0.80} \mathrm{O}_{3}$ lead-free subtransparent ceramics was prepared by conventional ceramics sintering technique. The refractive indexes of the films were investigated by an ellipsometer, and analyzed by Cauchy dispersion model. The relationship between the structure and the optical properties was also investigated, which might be an aid in developing a process for fabricating the transparent ceramics by conventional sintering technique.

\section{Experimental}

\subsection{Preparation of the pure and La doped KNLTN ceramics}

Pure KNLTN and KNLTN-La 0.01 lead-free subtransparent ceramics were prepared by conventional ceramics sintering technique. High-purity $(99.99 \%)$ potassium carbonate $\left(\mathrm{K}_{2} \mathrm{CO}_{3}\right)$, sodium carbonate $\left(\mathrm{Na}_{2} \mathrm{CO}_{3}\right)$, lithium carbonate $\left(\mathrm{Li}_{2} \mathrm{CO}_{3}\right)$, niobium oxide $\left(\mathrm{Nb}_{2} \mathrm{O}_{5}\right)$, tantalum oxide $\left(\mathrm{Ta}_{2} \mathrm{O}_{5}\right)$ and lanthanum oxide $\left(\mathrm{La}_{2} \mathrm{O}_{3}\right)$ were used as raw materials. They were milled in polytetrafluoroethylene with $\mathrm{ZrO}_{2}$ balls for 48 hours using ethanol as a medium. After calcination at $800{ }^{\circ} \mathrm{C}$ for 4 hours, the calcined powders were ball milled again for 48 hours, dried and then polyvinyl alcohol (PVA) was added as a binder. Subsequently, the powders were granulated and were allowed to pass through a $100 \mu \mathrm{m}$ mesh to break the agglomerates. Then they were pressed into pellets of $13 \mathrm{~mm}$ diameter under $250 \mathrm{MPa}$. The sintering temperature was chosen in a range of 1120 to $1140{ }^{\circ} \mathrm{C}$, since the maximum shrinkage was shown in this temperature range. The duration of sintering was 4 hours. The bulk densities were obtained by Archimedes method.

\subsection{Characterization of the ceramics}

The crystal phase structures were monitored by X-ray powder diffraction (XRD-6000, Shimadzu, Japan) with $\mathrm{Cu} \mathrm{K} \alpha$ radiation. The microstructures were studied with a scanning electron microscope (SEM, S-4700, Hitachi, Japan) and the surface and fracture topographies were detected by scanning probe microscopy (SPM, CSPM500, Ben Yuan Ltd., China). The transmissivity and reflectivity of the sample were tested with two lasers at different wavelength (532 nm and $632.8 \mathrm{~nm}$, respectively) under the same conditions. Furthermore, the refractive index dispersion behavior of the sample was investigated on an ellipsometer $\left(\alpha-S E^{T M}\right.$, J.A. Woollam Co., Inc., America).

\section{Results and discussion}

\subsection{Optical properties of the KNLTN- $\mathbf{L a}_{0.01}$ lead-free subtransparent ceramics}

The photographs of the pure KNLTN and KNLTN-La ${ }_{0.01}$ ceramics are given in Fig. 1. It can be seen that the transparency of the pure KNLTN is obviously weaker than that of the La doped ceramics with the same thickness about $1 \mathrm{~mm}$. Although the optical transparency cannot reach the value of optical glass and the high transparent ceramics, the KNLTN-La 0.01 ceramics with certain transparency were successfully prepared by a conventional ceramics sintering technique.

In order to further examine the optical transparency of the samples, the $532 \mathrm{~nm}$ and $632.8 \mathrm{~nm}$ lasers were used to test the transmissivity and reflectivity of the samples under the same conditions and the test results are listed in Table 1. As it can be seen from Table 1, the transmissivity of high 
Table 1. Transmission and reflection of the ceramics.

\begin{tabular}{ccccc}
\hline$\lambda(\mathrm{nm})$ & $\begin{array}{c}\text { High density KNLTN-La } 0.01 \\
(>97 \%)\end{array}$ & $\begin{array}{c}\text { Low density ceramic sample } \\
\text { (pure KNLTN ceramics) }\end{array}$ \\
\cline { 2 - 5 } & Transmissivity (\%) & Reflectivity (\%) & Transmissivity (\%) Reflectivity (\%) \\
\hline \hline 532 & 4.5 & 8.6 & $<0.1$ & $<10.5$ \\
632.8 & 4.9 & 9.6 & $<0.7$ & $<11.2$ \\
\hline
\end{tabular}

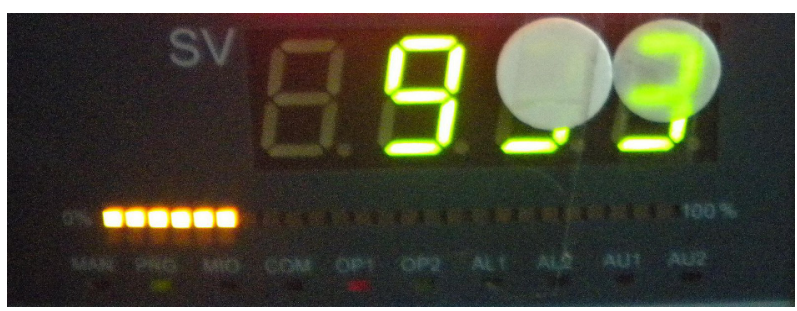

Fig. 1. Photograph illustrating the transparency of pure KNLTN (left) and KNLTN-La 0.01 (right) ceramics.

density KNLTN-La 0.01 ceramic sample is nearly $5 \%$, which is one order of magnitude higher than that of the pure KNLTN sample. The reflectivity of the KNLTN-La $\mathrm{a}_{0.01}$ ceramics is slightly lower than that of the pure KNLTN ceramics, and the reflectivity of two kinds of samples is close to $10 \%$ within the measurement uncertainties. The results do not show any significant difference in the reflectivity of the samples because the polishing processes of the ceramics were the same. However, the transparencies of the ceramics are still lower than those in the KNLTN crystals and high transparent La doped PZT ceramics prepared by hot-pressing $[15,16]$.

The refractive indexes $\mathrm{n}$ and the extinction coefficients $\mathrm{k}$ of the transparent KNLTN- $\mathrm{La}_{0.01}$ ceramics in the wavelength range from $380 \mathrm{~nm}$ to $900 \mathrm{~nm}$ are shown in Fig. 2. Their values were derived from the experimental results of the ellipsometer at room temperature at the incident angle of $70^{\circ}$. As the crystal cell parameters of prepared ceramics are similar, the birefringence effect has not been considered in the calculation and the analysis of the nature of the sample [17].

The wavelength dependence of the refractive indexes of the tested sample shows the typical shape of a normal dispersion curve. It can be seen from

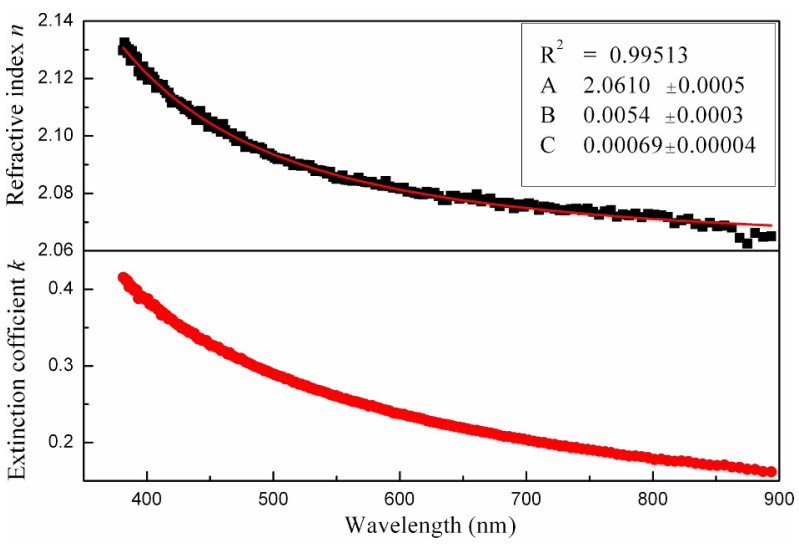

Fig. 2. Refractive index dispersive properties of KNLTN-La ${ }_{0.01}$ ceramics.

Fig. 2 that the refractive index $\mathrm{n}$ and extinction coefficient $\mathrm{k}$ of the KNLTN-La 0.01 ceramics decrease with the increase of wavelength from $380 \mathrm{~nm}$ to $900 \mathrm{~nm}$. The extinction coefficient $\mathrm{k}$ is very small when the wavelength is longer than $600 \mathrm{~nm}$, where the films are nearly transparent. When the wavelength is shorter than $400 \mathrm{~nm}$, the extinction coefficient $\mathrm{k}$ becomes bigger. The possible reason is that the wavelength approaches KTN material absorption band of near $370 \mathrm{~nm}$ [18].

It is well known that the frame of $\mathrm{ABO}_{3}$ structure is $\mathrm{BO}_{6}$ oxygen octahedron, which is closely related to the wavelength dependent refractive dispersion $[16,19]$. The refractive index dispersion curve of the ceramics could be described by the Cauchy model of three parameters:

$$
n=A+\frac{B}{\lambda^{2}}+\frac{C}{\lambda^{4}}
$$

where the unit of $\lambda$ is $\mu \mathrm{m}, \mathrm{A}, \mathrm{B}, \mathrm{C}$ are all Cauchy dispersion constants with the values of $2.0610 \pm 0.0005, \quad 0.0054 \pm 0.0003$ and 
0.00069 \pm 0.00004 , respectively, as shown in Fig. 2 . The solid black squares are the experimental data, and the thin red line is the Cauchy model fitting. The results show that the correlation coefficient of fitting curve is greater than $99.5 \%$. The refractive index decreases with increasing wavelength, and its numerical value is between 2.06 to 2.14 for wavelength $380 \mathrm{~nm}$ to $900 \mathrm{~nm}$.

Refractive indexes of KNLTN-La 0.01 and other similar ceramics at three different wavelengths are listed in Table 2. The refractive index of KNLTN$\mathrm{La}_{0.01}$ ceramic sample is slightly smaller than the refractive indexes of tantalum niobate crystals and $\mathrm{KTa}_{0.5} \mathrm{Nb}_{0.5} \mathrm{O}_{3}$ films on $\mathrm{Pt} / \mathrm{Ti} / \mathrm{SiO}_{2} / \mathrm{Si}$ substrates, as shown in Table $2[16,17,20,21]$. It is a little bigger than that of $\mathrm{KTa}_{0.5} \mathrm{Nb}_{0.5} \mathrm{O}_{3}$ films on $\mathrm{Si}$ (001) substrates [22], which indicates the good optical properties of the KNLTN-La ${ }_{0.01}$ ceramics. In addition, KNLTN-La $\mathrm{L}_{0.01}$ ceramics extinction coefficient $(0.15$ to 0.42$)$ decreases with the increasing wavelength in the measurement range. The extinction coefficient is related to the material absorption; the sample extinction coefficient is bigger than 0.3 when the wavelength is less than $500 \mathrm{~nm}$. The relatively large extinction coefficient of the ceramic sample indicates that the sample absorption is strong, which is consistent with the small transmittance values of the ceramic samples in Table 1 .

\subsection{Structure characterization of the ceramics}

In order to further investigate the reason of low transparency, smaller refractive index and the slightly larger extinction coefficient of KNLTN$\mathrm{La}_{0.01}$ ceramic sample, the XRD (X-ray diffraction) and SEM (scanning electron microscope) results were used to characterize the ceramics surface structure and its microstructure. The room temperature XRD patterns of the KNLTN and KNLTN-La ${ }_{0.01}$ ceramics are shown in Fig. 3. The crystallographic indexing is of perovskite type, and no other structure is observed. The (002)/(200) peak splitting occurs at about $2 \theta=$ $45^{\circ}$ and the crystallographic indexing of the diffraction peaks reveals the formation of KNLTN$\mathrm{La}_{0.01}$ ceramics with $\mathrm{ABO}_{3}$ perovskite structure, tetragonal phase and $\mathrm{P} 4 \mathrm{~mm}$ point group [23]. The pure KNLTN ceramics exhibits a transitional phase, which is mixed with tetragonal and orthorhombic phases [24, 25]. It is well known that the orthorhombic-tetragonal phase transition temperature of $\mathrm{KNN}$ is about $200{ }^{\circ} \mathrm{C}$, and it decreases to the room temperature when $20 \%$ $\mathrm{Nb}$ atoms and $4 \% \mathrm{~K}$ and/or $\mathrm{Na}$ atoms are replaced by $\mathrm{Ta}$ and $\mathrm{Li}$ atoms in the KNN ceramics. The mixed phase indicates the orthorhombictetragonal phase transition temperature of the KNLTN ceramics, which is close to room temperature. Furthermore, the subtle difference in XRD patterns of KNLTN and KNLTN-La ${ }_{0.01}$ ceramics reveals that the orthorhombic-tetragonal phase transition temperature of KNLTN-La 0.01 is higher than that of KNLTN ceramics. In other words, the orthorhombic-tetragonal phase transition temperature increases slightly due to the introduction of $\mathrm{La}$ element.

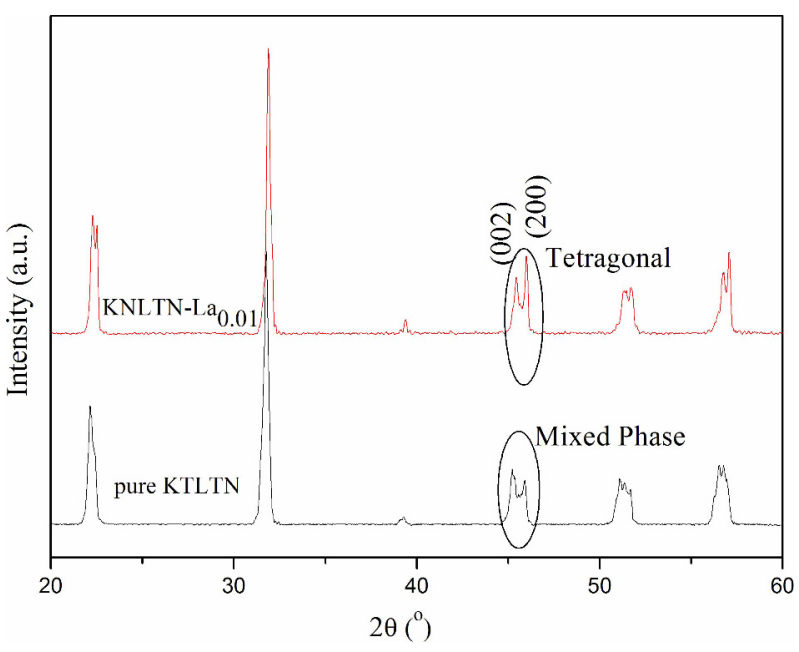

Fig. 3. XRD pattern of pure KNLTN and KNLTN$\mathrm{La}_{0.01}$ ceramics.

Fig. 4 exhibits the SEM micrographs taken from the surface and fractured sections of pure and $\mathrm{La}$ doped KNLTN ceramics. As can be seen from the surface images of the KNLTN-La ${ }_{0.01}$ ceramics and the surface of pure KNLTN (Fig. 4a, 4b and 4f), all the samples have dense structures and a few micro holes. The pure KNLTN samples consist of small grains of about $5 \mu \mathrm{m}$ (Fig. 4f). On the other hand, the grains are not well distinguished 


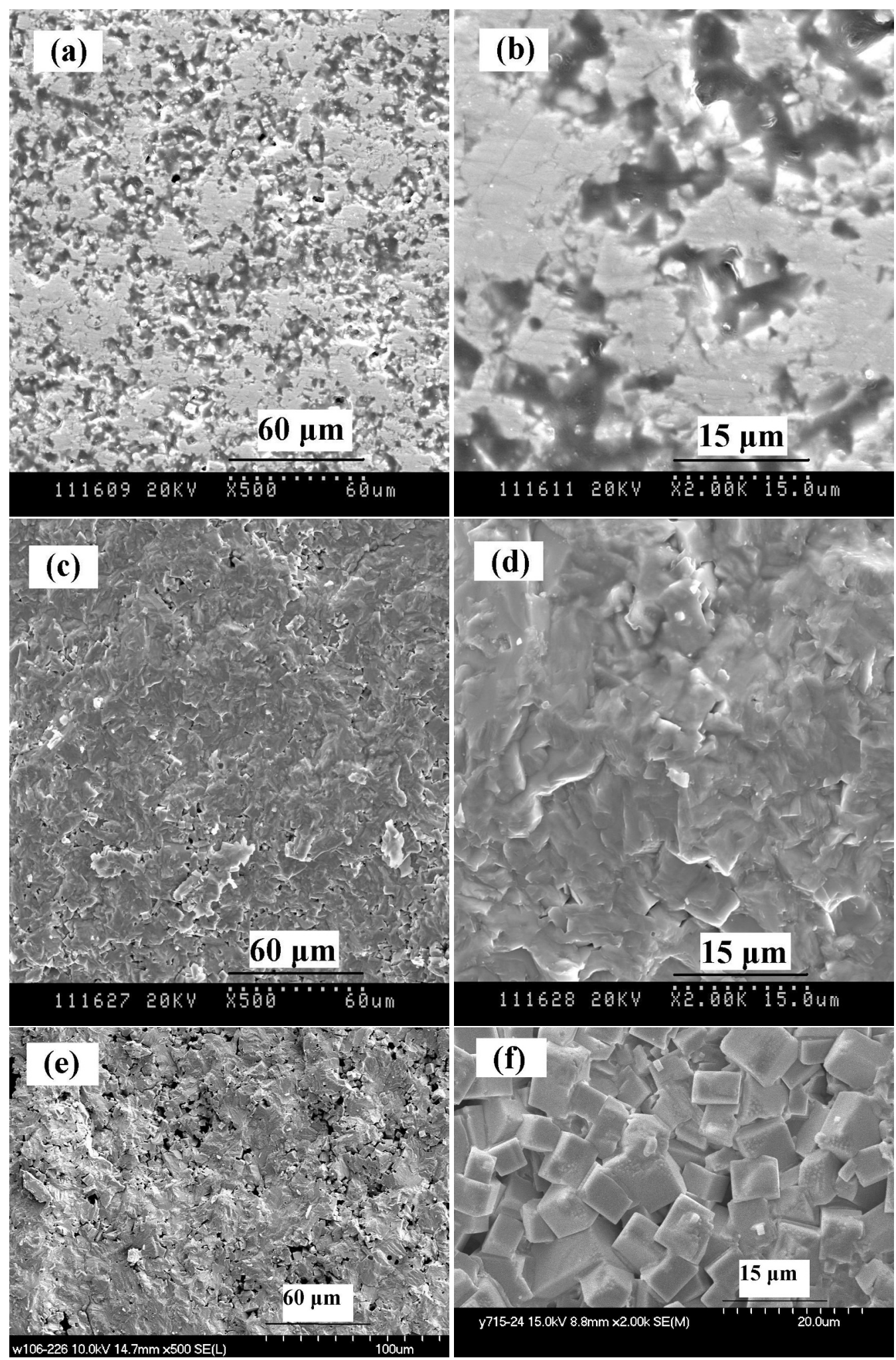

Fig. 4. Surface and fractured section SEM micrographs of pure KNLTN and KNLTN-La 0.01 ceramics; (a) and (b) surface micrographs of KNLTN-La 0.01 ceramics; (c) and (d) fractured section micrographs of KNLTN$\mathrm{La}_{0.01}$ ceramics; (e) fractured section micrographs of pure KNLTN ceramics; (f) surface section micrographs of pure KNLTN ceramics. 
Table 2. Refractive indexes of alkali metal tantalate niobate materials at different wavelength.

\begin{tabular}{cccc}
\hline Wavelength (nm) & 546.1 & 589.3 & 632.8 \\
\hline \hline $\mathrm{KNLTN}_{\mathrm{L}} \mathrm{La}_{0.01}$ ceramics & 2.086 & 2.084 & 2.078 \\
$\mathrm{KTa}_{0.48} \mathrm{Nb}_{0.52} \mathrm{O}_{3}$ crystals [16] & 2.324 & 2.301 & 2.284 \\
$\mathrm{KTa}_{0.65} \mathrm{Nb}_{0.35} \mathrm{O}_{3}$ crystals [17] & 2.323 & 2.302 & 2.286 \\
$\mathrm{KTa}_{0.5} \mathrm{Nb}_{0.5} \mathrm{O}_{3} / \mathrm{Pt}_{(111) / \mathrm{Ti} / \mathrm{SiO}_{2} / \mathrm{Si} \text { film }[20]} 2.303$ & 2.289 & 2.279 \\
$\mathrm{~K} \mathrm{Ta}_{0.5} \mathrm{Nb}_{0.5} \mathrm{O}_{3} / \mathrm{MgO}$ films [21] & - & - & 2.2396 \\
$\mathrm{~K} \mathrm{Ta}_{0.5} \mathrm{Nb}_{0.5} \mathrm{O}_{3} / \mathrm{Si}(001)$ film [22] & 2.020 & 1.994 & 1.972 \\
\hline
\end{tabular}

in the KNLTN-La 0.01 ceramic sample, which indicates the compact structure of the transparent ceramics. The improvement of the microstructure compared with the pure ceramics reveals the advantageous effect of the La element; in other words, $\mathrm{La}_{2} \mathrm{O}_{3}$ served as a sintering aid to improve the density of the ceramics. It can also be seen that all the ceramics exhibit intracrystalline fractured structure, as shown in Fig. 4c, 4d and 4e.

The grains are more pronounced around the microholes for both KNLTN-Laa 01 and pure ceramics. It is important to point out that the quantity of the micro holes decreases in the bulk of the ceramics after the La added into the KNLTN. The higher density, combined with compacted grains and less number of microholes, might be the main reason for the KNLTN-La $\mathrm{L}_{0.01}$ ceramic becomes somewhat transparent. On the other hand, the density of the KNLTN-La 0.01 ceramics, measured using Archimedes method, is above $97 \%$; however, it is still smaller than the density of a crystal and the transparent ceramics prepared by hotpress method, which could be the reason for weaker transparency of the KNLTN-La 0.01 compared with the hot-pressed ceramics $[1-3,10]$.

The ceramic sample density after sintering process has been improved and refined. It is one of the reasons why the KNLTN-La 0.01 ceramics shows certain visible light transmittance, but the sample density of $97 \%$ is still lower compared to that of hot-pressing prepared PLZT transparent ceramics with density of $99.8 \%$. The existing microporous defects, not only directly lower the density of the ceramics and the material uniformity, but also cause relatively strong light absorption, reflection, scattering and so on, thus, reducing the visible light transmittance of the sample. We believe that further optimization of ceramics sintering process by increasing the ceramics molding pressure, extending appropriately the ball milling time of the powder and increasing the uniformity of the powder to further improving the ceramics density, may be an effective way to enhance the transparency of the opto-ceramics.

\section{Conclusions}

The KNLTN and KNLTN-La 0.01 lead-free ceramics were prepared by conventional ceramics sintering technique, and the subtransparent KNLTN-La 0.01 ceramics were obtained. The optical properties were investigated and the results reveal that the KNLTN-La 0.01 subtransparent ceramics shows significant wavelength dependent dispersion in 380 to $900 \mathrm{~nm}$ range. The refractive index decreases from 2.14 to 2.06 with increasing wavelength within the measurement range. The dispersive behavior was analyzed by three parameters of Cauchy dispersion model, A, B and C, whose values were $2.0610 \pm 0.0005,0.0054 \pm 0.0003$ and $0.00069 \pm 0.00004$, respectively. In order to find the relationship between the optical properties and the structure of the ceramics, the room temperature crystallographic indexing and SEM were employed. The results reveal that the KNLTN-La $\mathrm{La}_{0.01}$ ceramics is of $\mathrm{ABO}_{3}$ perovskite type, tetragonal phase and $\mathrm{P} 4 \mathrm{~mm}$ point group. The existence of visible porous structures and the ceramics density were considered as the main reason for observed transparent properties of the ceramics.

\section{Acknowledgements}

This work was supported by the Scientific Research Fund of Heilongjiang Provincial Education Department (No. 12531115). 


\section{References}

[1] Uciryama K., Shiosaki T., Kosaka T., Kasamatsu A., Echizen M., Ceram. Int., 34 (2008), 979.

[2] Wang S.F., Zhang J., LuO D.W., Gu F., TAng D.Y., DOng Z.L., TAN G.E.B., QuE W.X., ZHANG T.S., LI S., Kong L.B., Prog. Solid State Ch., 41 (2013), 20.

[3] Wu Z.C., Zhang X.L., Optik, 124 (2013), 3457.

[4] Murade P.A., Sangawar V.S., Chaudhari G.N., KAPSE V.D., BAJPEYEe A.U., Mater. Sci.-Poland, 31 (2013), 298.

[5] Stafiniak A., Boratyński B. B., BaranowskaKorCZyC A., Fronc K., Elbaum D., PASZKIEWICZ R., TŁACZAŁA , Mater. Sci.-Poland, 31 (2013), 312.

[6] Li F.L., Kwok K.W., J. Eur. Ceram. Soc., 33 (2013), 123.

[7] Haertling G.H., Ferroelectrics, 75 (1987), 25.

[8] Sternberg A., Ferroelectrics, 91 (1989), 53.

[9] Li K., Li F. L., WANG Y., KwOK K. K., Chan H. L. W., Mater. Chem. Phys., 131 (2011), 320.

[10] KwoK K.W., Li F.L., LiN D., Funct. Mater. Lett., 4 (2011), 237.

[11] Haertling G.H., Landf C.E., J. Am. Ceram. Soc., 5 (1971), 1.

[12] Li K.K., WAng W., US Patent, 2004.

[13] Choi J.J., Ryu J., Kim H.E., J. Am. Ceram. Soc., 84 (2001), 1465.

[14] Haertling G.H., J. Am. Ceram. Soc., 54 (1971), 303.
[15] Haertling G.H., J. Am. Ceram. Soc., 54 (1971), 221.

[16] Loheide S., RiehemanN S., Mersch F., Pankrath P., Kratzing E., Phys. Status Solidi A, 137 (1993), 257.

[17] Chen F.S., Geusic J.E., Kurtz S.K., J. Appl. Phys., 37 (1966), 388.

[18] Zheng K.Y., Zhang D.M., ZHONG Z.C., YANG F.X., Han X.Y., Appl. Surf. Sci., 256 (2009), 1317.

[19] Liu A., Xue J., Meng X., Sun J., Huang Z., Chu J., Appl. Surf. Sci., 254 (2008), 5660.

[20] YAng W.L., Zhou Z.X., YAng B., JiAng Y.Y., Tian H., Gong D.W., Sun H.G., Chen W., Appl. Surf. Sci., 257 (2011), 7221.

[21] Rousseau A., Viry M.G., Dongheche E., J. Appl. Phys., 102 (2007), 093106.

[22] Yang W.L., Zhou Z.X., Yang B., Jiang Y.Y., Pei Y.B., Sun H.G., WANG Y., Appl. Surf. Sci., 258 (2012) 3986.

[23] Wang K., Li J.F., Appl. Phys. Lett., 91 (2007), 262902.

[24] Zhou J.J., Li J.F., Wang K., Zhang X.W., J. Mater. Sci., 46 (2011), 5111.

[25] Dai Y.J., Zhang X.W., Zhou G.Y., Appl. Phys. Lett., 90 (2007), 262903. 